\title{
Smart, Naturally-Derived Macromolecules for Controlled Drug Release
}

\author{
Izabela Zaborniak ${ }^{1}$ (D), Angelika Macior ${ }^{2}$ and Paweł Chmielarz ${ }^{1, *(D)}$ \\ 1 Department of Physical Chemistry, Faculty of Chemistry, Rzeszow University of Technology, Al. Powstańców \\ Warszawy 6, 35-959 Rzeszów, Poland; d410@stud.prz.edu.pl \\ 2 Doctoral School of Engineering and Technical Sciences at the Rzeszow University of Technology, Al. \\ Powstańców Warszawy 8, 35-959 Rzeszów, Poland; d519@stud.prz.edu.pl \\ * Correspondence: p_chmiel@prz.edu.pl; Tel.: +48-17-865-1809
}

Citation: Zaborniak, I.; Macior, A.; Chmielarz, P. Smart, NaturallyDerived Macromolecules for Controlled Drug Release. Molecules 2021, 26, 1918. https://doi.org/ $10.3390 /$ molecules 26071918

Academic Editor: Bhanu P.

S. Chauhan

Received: 14 February 2021

Accepted: 24 March 2021

Published: 29 March 2021

Publisher's Note: MDPI stays neutral with regard to jurisdictional claims in published maps and institutional affiliations.

Copyright: (c) 2021 by the authors. Licensee MDPI, Basel, Switzerland. This article is an open access article distributed under the terms and conditions of the Creative Commons Attribution (CC BY) license (https:// creativecommons.org/licenses/by/ $4.0 /)$.

\begin{abstract}
A series of troxerutin-based macromolecules with ten poly(acrylic acid) (PAA) or poly(2dimethylaminoethyl methacrylate) (PDMAEMA) homopolymer side chains were synthesized by a supplemental activator and reducing agent atom transfer radical polymerization (SARA ATRP) approach. The prepared precisely-defined structures with low dispersity $\left(M_{\mathrm{w}} / M_{\mathrm{n}}<1.09\right.$ for PAAbased, and $M_{\mathrm{w}} / M_{\mathrm{n}}<1.71$ for PDMAEMA-based macromolecules) exhibited $\mathrm{pH}$-responsive behavior depending on the length of the polymer grafts. The properties of the received polyelectrolytes were investigated by dynamic light scattering (DLS) measurement to determine the hydrodynamic diameter and zeta potential upon $\mathrm{pH}$ changes. Additionally, PDMAEMA-based polymers showed thermoresponsive properties and exhibited phase transfer at a lower critical solution temperature (LCST). Thanks to polyelectrolyte characteristics, the prepared polymers were investigated as smart materials for controlled release of quercetin. The influence of the length of the polymer grafts for the quercetin release profile was examined by UV-VIS spectroscopy. The results suggest the strong correlation between the length of the polymer chains and the efficiency of active substance release, thus, the adjustment of the composition of the macromolecules characterized by branched architecture can precisely control the properties of smart delivery systems.
\end{abstract}

Keywords: troxerutin; smart delivery systems; ATRP; polyelectrolytes

\section{Introduction}

Smart polymers are a class of dynamically developing macromolecules with potential use in life science and pharmaceutical fields. They respond to environmental conditions mimicking the behavior of structures and functions of living organisms to adapt to variations in nature. Stimuli-responsive and switchable polymers react through physical or chemical changes, automatically adapting their properties to even small changes in the microenvironment, e.g., temperature, $\mathrm{pH}$, light, redox potential, etc. [1,2]. As a consequence of their sensitivity to external stimuli, such polymeric materials are widely considered as carriers of active substances, e.g., drugs [1,3], active substances [4,5], and genes [6,7], creating intelligent controlled delivery systems with slow, sustained release of substances.

Macromolecules with branched architectures are privileged as smart polymer materials due to their unique morphologies and properties. Complex macromolecules consist of many linear polymers attached to one core with a large number of chain-end functionalities. Owing to these characteristics, polymers with multiple side chains/arms exhibit some remarkable properties unattainable by simple linear polymers. Considering smart materials, macromolecules with branched architectures have strengthened action as a result of many polymer grafts stabilized by one core compared to their linear counterpart, thus, the ability to form unimolecular micelles, and efficiently transport active substances encapsulated within polymer side chains [8-11]. 
Star-like polymers and polymer brushes have found numerous applications as different stimuli-responsive polymers delivering drugs [1,2], and recently they were developed as an efficient active substance delivery system examined in vivo in tomatoes [4]. Drug delivery systems used in a live organism with controlled release of an active substance in individual sections of the digestive system need to be sensitive mostly to $\mathrm{pH}$ changes. Several polymers are known to change their conformation upon $\mathrm{pH}$ changes. Poly(acrylic acid) (PAA) received in a facile way as a result of poly(tert-butyl acrylate) (PtBA) acidolysis is a typical polymer that can respond to changes in $\mathrm{pH}$. Under pKA $(\sim 4.5)$ carboxylate groups located in a PAA chain are protonated, and the molecules have a compact and collapsed structure, while in alkaline conditions macromolecules are fully stretched due to deprotonation of carboxyl groups, resulting in electrostatic repulsion between $-\mathrm{COO}^{-}$ moieties [12,13]. Moreover, PAA does not have a significant effect on the proliferation of living cells, therefore, it exhibits high biocompatibility, and has great potential for use as smart drug delivery systems in the human organism [13,14]. Another type of $\mathrm{pH}-$ responsive polymer is poly(2-dimethylaminoethyl methacrylate) (PDMAEMA), which contains tertiary amine functional groups. Conversely to PAA chains, in an acidic medium free amino groups located in PDMAEMA are ionized and the structure is extended, while under alkaline conditions many hydrogen bonds are created among amino groups, and the macromolecules adopt compact conformation $[15,16]$. Moreover, PDMAMEMA exhibits phase separation at the lower critical solution temperature (LCST) in aqueous media, thus, it is a thermoresponisive polymer [17]. Polycations like PDMAEMA are highly promising non-viral gene delivery agents and are able to site-specifically deliver active substances; however, their use in living organisms is limited due to toxicity against healthy cells [18].

There are many works presenting the use of branched polymers for in vitro controlled release of drugs, e.g., doxorubicin [13,19], curcumin [5,20], etc., upon $\mathrm{pH}$ changes. They are also considered carriers for active substances in the plant. Smart materials with agrochemical use are increasingly investigated to improve the efficiency and uptake of pesticide, fungicide and micronutrients, and to avoid damage to plants by acidic or alkaline environment, e.g., due to acid rains, or a large amount of plant protection products that are washed off the leaves. The reduction of pollutants related to the high amount of products used to efficiently protect the plant is possible by controlled release of the active substances in the plant when they are needed-when an unfavorable stimulus acts on the plant $[21,22]$.

To precisely determine the properties of smart materials and to thoroughly drive the action, the knowledge about its chemical structure, thus, its well-defined architecture, is mandatory [23]. Polymers with predetermined structures and branched architecture are widely provided by atom transfer radical polymerization (ATRP) techniques, especially with low catalyst concertation avoiding contamination of the final polymer product [24-27]. As a result of a precisely controlled equilibrium between active and dormant species driven by catalytic complex, the growth of polymer grafts is precisely controlled and the polymers with predetermined structure and properties are able to receive [28-31]. Branched polymers are usually prepared by ATRP techniques using the grafting-from concept, i.e., the modification of a substrate containing ubiquitous hydroxyl groups with bromine is initially conducted, followed by polymerization of monomers from incorporated ATRP initiation sites [32-34].

In order to receive biocompatible and biodegradable structures with great potential for use in live organisms by means of ATRP techniques, naturally-derived substrates are increasingly used as macromolecular cores [35]. Troxerutin is a natural bioflavonoid-a trihydroxyethylated derivative of rutin that can be found in tea, coffee, and a variety of fruits and vegetables [36,37]. As a polyphenol structure, it was successfully modified by the ATRP approach to enhance its lipophilicity and, thus, bioavailability, modifying it with hydrophobic poly( $n$-butyl acrylate) ( $\mathrm{P} n \mathrm{BA})$ chains [35]. The presented work shows the facile route for the use of this naturally-derived flavonoid glycoside for preparing smart polymeric materials, namely $\mathrm{pH}$-responsive polymers for controlled release in a live organism, both human or plants. The novel macromolecules with varying length of 
PAA or PDMAEMA side chains and troxerutin core were synthesized to examine their $\mathrm{pH}$ responsiveness as a function of the lengths of polymer grafts. The quercetin $(\mathrm{QC})$ release profile from monomolecular micelles composed of prepared macromolecules was studied.

\section{Results and Discussion}

2.1. Synthesis and Characterization of pH-Responsive Troxerutin-Based Star-Shaped Polymers with Different Arm Lengths

Star-like macromolecules with 10 polymer arms and troxerutin core were synthesized by a two-step synthesis route according to the core-first concept (Figure 1).

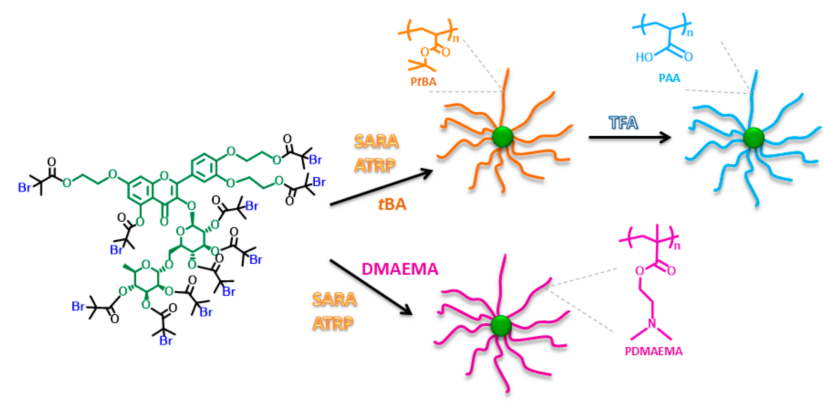

Figure 1. Synthetic route for the preparation of troxerutin-based polyelectrolytes.

Hydroxyl groups located in troxerutin substrate were functionalized with $\alpha$-bromoisobutyryl bromide (BriBBr) to form an ATRP initiator molecule as previously described in detail [35]. The supramolecular bromide initiator was subsequently polymerized with tert-butyl acrylate ( $t \mathrm{BA}$ ) - an excellent substrate for receiving $\mathrm{pH}$-responsive acrylic acid (AA) moieties in the proposed synthetic route. Acidic hydrolysis with trifluoroacetic acid (TFA) under ambient conditions is widely used for the transformation of tert-butyl groups into carboxylic acid [5]. The SARA ATRP approach with the use of copper wire $\left(\mathrm{Cu}^{0}\right)$ with only $165 \mathrm{ppm}$ by weight of catalyst was applied for the synthesis of PtBA polymer arms grafted from the troxerutin core. Three types of macromolecules with varying lengths of polymer grafts were received by applying different target degrees of polymerization $\left(\mathrm{DP}_{\text {target }}\right)$ in syntheses (Table 1, entry 1-3).

Table 1. Synthesis of star-shaped macromolecules composed of troxerutin core and PtBA or PDMAEMA side chains via the SARA ATRP technique.

\begin{tabular}{|c|c|c|c|c|c|c|c|c|c|c|}
\hline Entry & Monomer & $\mathrm{DP}_{\text {target }}$ & $\begin{array}{c}\text { Conv }^{1} \\
(\%)\end{array}$ & $\begin{array}{c}k_{\mathrm{p}^{\text {app 2 }}} \\
\left(\mathrm{h}^{-1}\right)\end{array}$ & $\begin{array}{c}\mathrm{DP}_{\mathrm{n}, \text { theo }}{ }^{1} \text { (per } \\
\text { chain) }\end{array}$ & $\begin{array}{l}M_{\mathrm{n}, \text { theo }}{ }^{3} \\
\left(\times 10^{-3}\right)\end{array}$ & $\begin{array}{l}M_{n, a_{p p}}{ }^{2} \\
\left(\times 10^{-3}\right)\end{array}$ & $M_{\mathrm{w}} / M_{\mathrm{n}}^{4}$ & $\begin{array}{c}d_{\text {number }}^{5} \\
(\mathrm{~nm})\end{array}$ & $d_{(\mathrm{nm})}^{d_{\text {number }}^{6}}$ \\
\hline 1 & $t \mathrm{BA}$ & 50 & 79 & 0.594 & 40 & 53.0 & 39.5 & 1.05 & $7.7 \pm 0.7$ & $3.4 \pm 0.3$ \\
\hline 2 & $t \mathrm{BA}$ & 100 & 67 & 0.609 & 67 & 88.6 & 66.7 & 1.05 & $10.6 \pm 0.7$ & $4.3 \pm 0.2$ \\
\hline 3 & $t \mathrm{BA}$ & 200 & 78 & 0.734 & 157 & 203.3 & 131.4 & 1.09 & $17.1 \pm 1.8$ & $6.6 \pm 0.7$ \\
\hline 4 & DMAEMA & 800 & 12 & 1.723 & 98 & 156.7 & 201.9 & 1.71 & - & $7.2 \pm 0.9^{7}$ \\
\hline
\end{tabular}

${ }^{1}$ Monomer conversion (Conv) and theoretical degree of polymerization ( $\mathrm{DP}_{\mathrm{n} \text {,theo }}$ ) calculated according to ${ }^{1} \mathrm{H}$ NMR analysis, $\left.\mathrm{DP}_{n \text {,theo }}=\left(\mathrm{Conv} \times[\mathrm{M}]_{0}\right) /\left[\mathrm{Trox}_{-\mathrm{Br}}\right]_{0}\right]_{0}$, where $\mathrm{M}$ denote monomer [38]; ${ }^{2}$ Apparent rate constant of propagation, calculated as a slope of the curve $\ln [\mathrm{M}]_{0} /[\mathrm{M}]=f(t)$ illustrated in the Figures 2a and $3 \mathrm{a}[38] ;{ }^{3} M_{\mathrm{n}, \text { theo }}=[\mathrm{M}]_{0} /\left[\operatorname{Trox}_{-} \mathrm{Br}_{10}\right]_{0} \times$ Conv $\times M_{\text {monomer }}+M_{\text {Trox-Br10 }} ;{ }^{4}$ Apparent $M_{n, a p p}$ and $M_{\mathrm{w}} / M_{\mathrm{n}}$ were determined by DMF GPC; ${ }^{5}$ Number mean diameter $\left(d_{\text {number }}\right)$ of PtBA-based polymers measured by DLS (in THF) after purification (Figure S9a,c,e); ${ }^{6}$ Number mean diameter $\left(d_{\text {number }}\right)$ of PAA-based polymers measured by DLS (in deionized water) after purification (Figure S9b,d,f); ${ }^{7}$ Number mean diameter $\left(d_{\text {number }}\right)$ of PDMAEMA-based polymers measured by DLS (in deionized water) after purification (Figure S10).

The polymerizations of $t \mathrm{BA}$ monomer from a naturally-derived core were described by a linear first-order kinetics plot (Figure 2a) and the molecular weight of star-shaped macromolecules steadily grew as monomer conversed (Figure $2 b$ ). It indicates a fully controlled syntheses of PtBA-based polymers. Moreover, as a result of precisely-controlled processes, polymer products with low dispersity $\left(M_{\mathrm{w}} / M_{\mathrm{n}}=1.05-1.09\right)$ (Figures S1a, S2a, 
and S3a) were received. Low molecular weight (LMW) impurities were noticed in the polymerization product (Figures S1b, S2b, and S3b). Their content increased with time, suggesting the transfer to solvent or monomer. However, this phenomenon did not affect the quality of the final macromolecules.

(a)

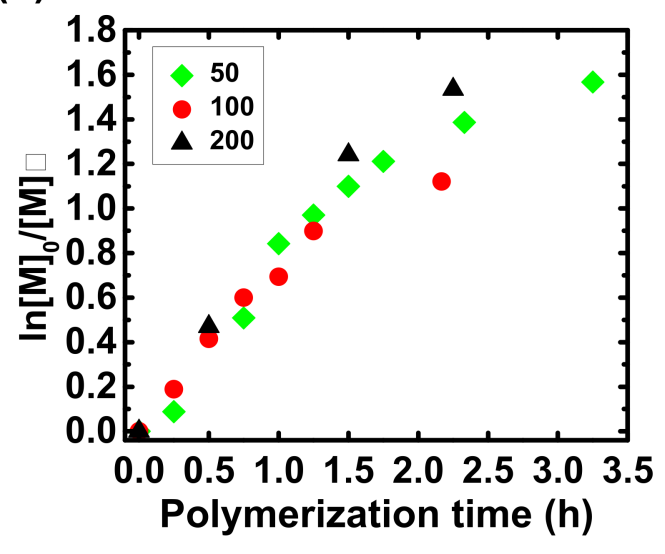

(b)

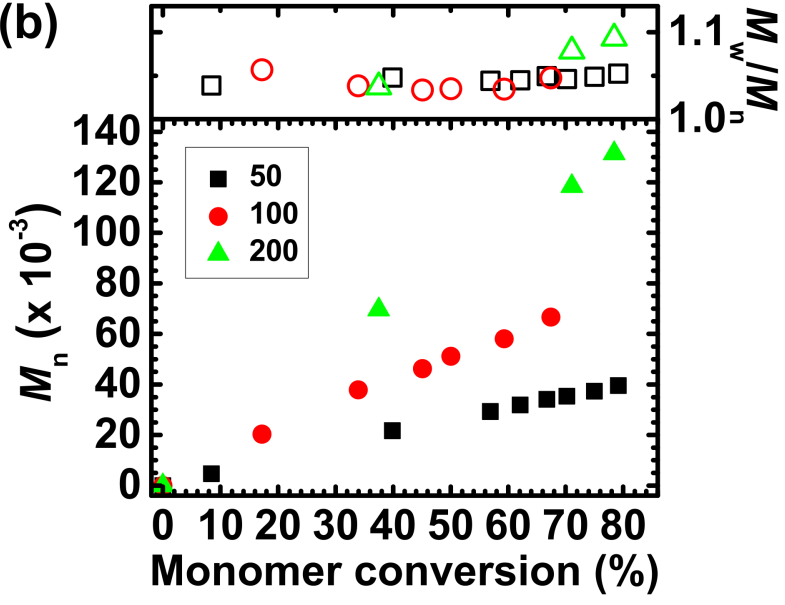

Figure 2. (a) First-order kinetics plot of monomer conversion vs. polymerization time of $t \mathrm{BA}$ from the troxerutin core with different target degrees of polymerization; (b) $M_{\mathrm{n}}$ and $M_{\mathrm{w}} / M_{\mathrm{n}}$ vs. monomer conversion. Table 1, entry 1-3.

Considering the kinetics aspect of the syntheses, the apparent rate constant of propagation decreases as the concentration of the initiator ([Trox- $\left.\mathrm{Br}_{10}\right]_{0}$ ) increases conversely to the rate of polymerization $\left(R_{\mathrm{p}}\right)$ equation $[39,40]$. This phenomenon is connected with the branched architecture of the received macromolecules. In the preparation of the linear polymers, there is no steric hindrance between growing macromolecules, while during the synthesis of star-shaped polymers the growing polymer side chains/arms located among one core can be entangled and slow down polymer growth, and thus monomer conversion. It is clearly visible on $\ln [\mathrm{M}]_{0} /[\mathrm{M}]$ versus the polymerization time plot. At the beginning of the process the rate constants are almost the same, while after ca. $1.5 \mathrm{~h}$ the polymerization with higher [Trox- $\left.\mathrm{Br}_{10}\right]_{0}$ is slowing down. The received PtBA-based macromolecules were hydrolyzed to sensitive to $\mathrm{pH}$ changes-PAA moieties. The structures of received polymers with PAA side chains were confirmed by ${ }^{1} \mathrm{H}$ NMR and FT-IR analysis (See details in Section S4. Proton nuclear magnetic resonance ( ${ }^{1} \mathrm{H}$ NMR) spectroscopy analysis of PtBA-, PAA-, and PDMAEMA-based macromolecules and Section S5. Fourier-transform infrared spectroscopy (FT-IR) analysis of star-shaped polymers).

Star-like polymers with troxerutin core and $\mathrm{pH}$ responsiveness opposite to PAA-based macromolecules were received by polymerization of DMAEMA from a flavonoid-based initiator. Analogously to PAA-based macromolecules, three different fractions with varying length of polymeric arms were obtained (Table 1, entry 4, Table S6). Deviation from the kinetics plot was observed, suggesting the slowing down of the polymerization as the process proceeds (Figure $3 a$ ). While the $M_{n}$ vs. monomer conversion curve deviates to higher molecular weight as the monomer is consumed (Figure 3b), it is connected with both characteristics of the ATRP initiator-densely packed initiation sites result in close proximity of polymer arms that terminate due to inter- and intramolecular coupling reaction, and monomer characteristics-DMAEMA can complex a catalyst and disturb the polymerization. Therefore, the received PDMAEMA-based macromolecules are characterized by slightly higher dispersity $\left(M_{\mathrm{W}} / M_{\mathrm{n}}=1.15-171\right)$ (Figure S4). 
(a)

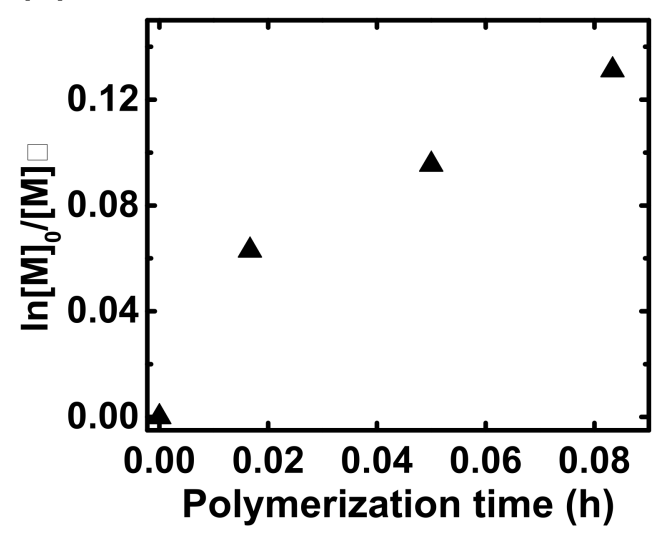

(b)

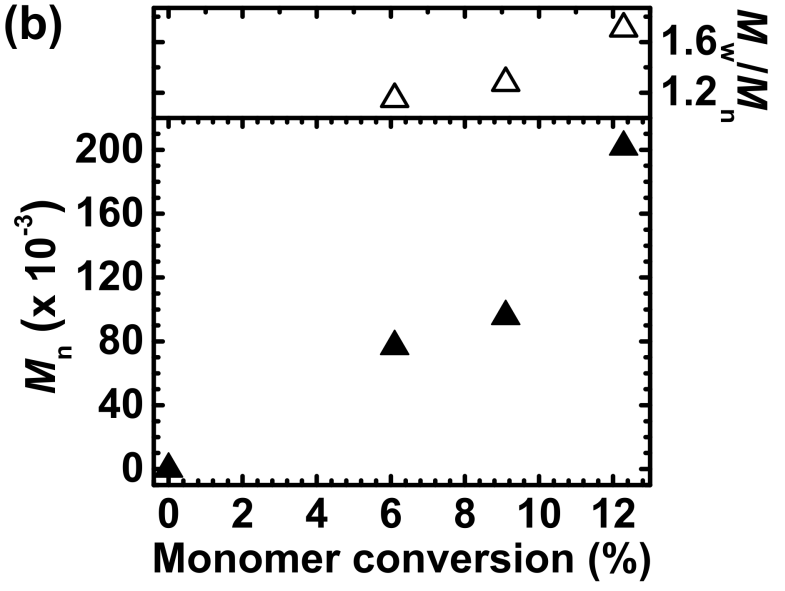

Figure 3. (a) First-order kinetic plot of monomer conversion vs. polymerization time of DMAEMA from the troxerutin core; (b) $M_{\mathrm{n}}$ and $M_{\mathrm{w}} / M_{\mathrm{n}}$ vs. monomer conversion. Table 1, entry 4.

The structure of received macromolecules was confirmed by ${ }^{1} \mathrm{H}$ NMR and FT-IR analysis (see details in Figure S4. Proton nuclear magnetic resonance $\left({ }^{1} \mathrm{H}\right.$ NMR) spectroscopy analysis of PtBA-, PAA-, and PDMAEMA-based macromolecules and Figure S5. Fourier-transform infrared spectroscopy (FT-IR) analysis of star-like polymers).

\subsection{Stimuli-Responsive Behavior of Troxerutin-Based Polymers}

Analysis of pH-responsive properties of PAA- and PDMAEMA-based star polymers was conducted by hydrodynamic radius and zeta potential measurements using the DLS method. Poly(acrylic acid) behavior and, thus, solubility in an aqueous solution is strictly connected with the state of ionization of the ubiquitous carboxylic groups present in its structure. Under the $\mathrm{pH}$ value $\sim 4.75$ (pKa of PAA [41]) carboxylate groups are fully protonated, the polymer has a compact globular conformation and becomes sparingly soluble in water. This follows from the transition of macromolecules characteristics from the hydrophilic to the hydrophobic one. Consequently, PAA-based star-like polymers turn amphiphilic, and the core-shell nanostructures are generated [11,42]. As clearly shown by hydrodynamic diameter measurements of Trox-(PAA-Br) 10 upon $\mathrm{pH}$ changes, below $\mathrm{pH} \sim 5\left(22^{\circ} \mathrm{C}\right)$ macromolecules were agglomerated, and the generated dispersion was rapidly and macroscopically precipitated (Figure $4 \mathrm{~b}$ ). This resulted in a significant increase in the diameter of nanoparticles (from $d_{\text {number }} \sim 13 \mathrm{~nm}$, through $\sim 650 \mathrm{~nm}$ in $\mathrm{pH}=5$, to $\sim 5,500 \mathrm{~nm}$ in $\mathrm{pH}=2$, Figure $4 \mathrm{a}$, Table S7). This phenomenon is related to insufficient steric interaction between particles because of non-charged PAA-based chains, thus the van der Waals attractive interactions are not counterbalanced [43,44]. Above $\mathrm{pH} \sim 5\left(22{ }^{\circ} \mathrm{C}\right)$ the diameter of polymers was $d_{\text {number }} \sim 11-13 \mathrm{~nm}$, indicating complete molecular dissolution of ionized polymers, and a fully solvated open coil conformation was formed. The results are consistent with $\zeta$-potential measurements. The particles dissolved in alkaline conditions possessed negative surface $\zeta$-potential up to $-32 \mathrm{mV}$. The charge decreased while the $\mathrm{pH}$ value decreased reaching $\zeta$-potential equal to $0 \mathrm{mV}$ at the isoelectric point (IEP, $\mathrm{pH}=3.56$ ). 
(a)

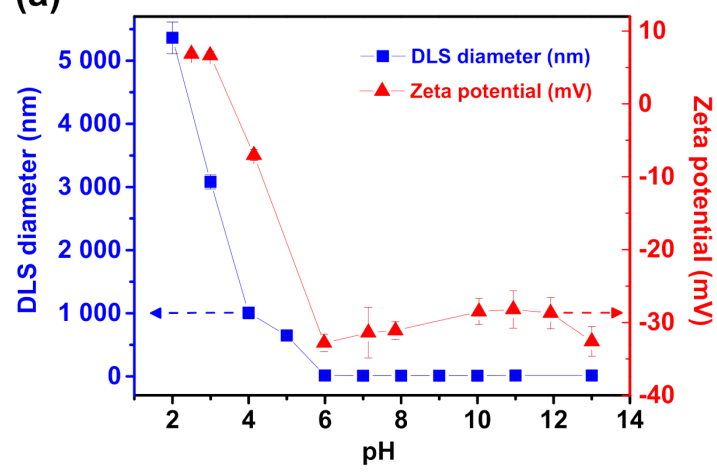

(b)

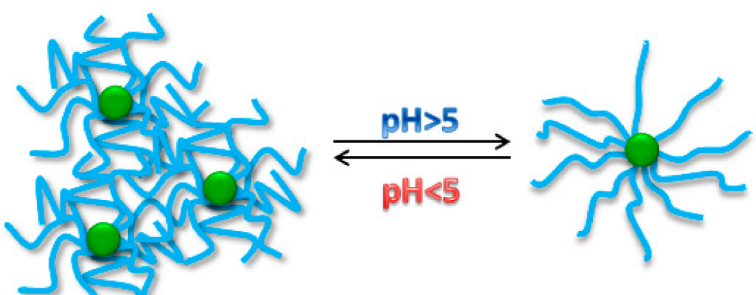

(c)

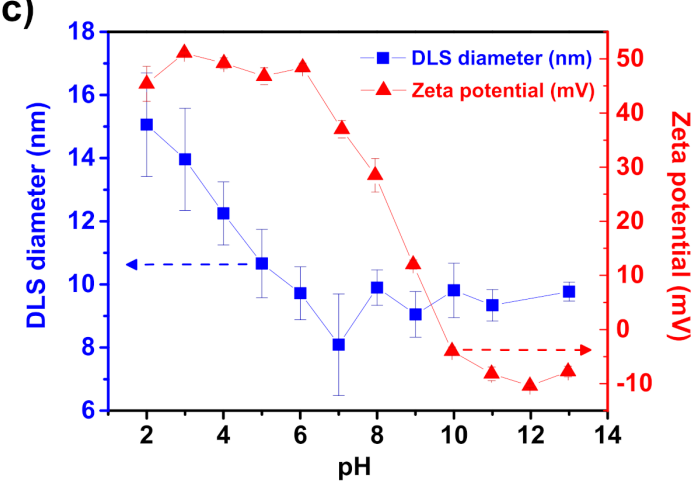

(d)

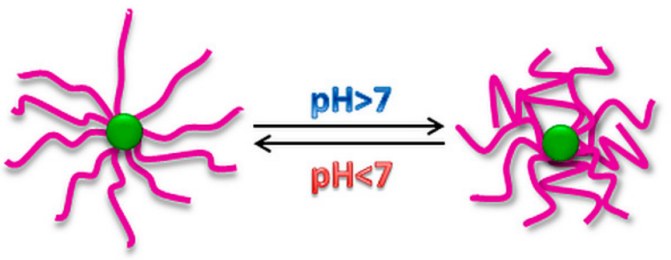

Figure 4. Effect of varying $\mathrm{pH}$ on number average sizes and zeta potential of the troxerutin-based macromolecules with (a) PAA and (c) PDMAEMA side chains; Scheme of pH-responsive behavior of (b) PAA and (d) PDMAEMA composed macromolecules with troxerutin core. The measurements conducted for final product from the syntheses shown in Table 1 , entry 3 and 4 , respectively.

A different phenomenon is observed in PDMAEMA-based monomolecular micelles. Although similar to PAA-based macromolecules, namely the higher hydrodynamic diameter value at acidic $\mathrm{pH}$, it is not due to the formation of micelle aggregates. At acidic $\mathrm{pH}$ the amine groups present among the PDMAEMA chains are fully protonated, and the polymer chains exhibit high surface charge densities [4,45]. This is proved by $\zeta$-potential measurements results: PDMAEMA macromolecules possessed positive surface $\zeta$-potential up to $51 \mathrm{mV}$. It increases the electrostatic repulsive forces that exist between the polymer side chains attached to the troxerutin core and the neighboring macromolecules. The hydrophilic polymer side chains self-assemble, avoiding the formation of the micellar aggregations, leading to the fully-expanded polymer chains and, thus, the highest hydrodynamic radius of PDMAEMA-containing monomolecular micelles (Figure 4c,d). As the $\mathrm{pH}$ value of an aqueous solution increases, the amine groups become increasingly deprotonated, electrostatic repulsive forces are significantly weaker, and $\zeta$-potential value becomes negative going through $0 \mathrm{mV}$ value in IEP $(\mathrm{pH}=9.70)$. It usually results in micellar growth due to an ability to more efficient packing of macromolecules [46-48]. Considering the prepared PDMAEMA-based macromolecules with troxerutin core, the polymer micelles exhibited lower hydrodynamic diameter than in acidic conditions. It suggests the stretching of the DMAEMA-based chains among the troxerutin core as a result of the loss of electrostatic repulsive forces between deprotonated chains, however, it occurs within one densely grafted (10 polymer chains attached to the core) macromolecule, and the aggregates are not formed.

Among the $\mathrm{pH}$ sensitivity, PDMAEMA also demonstrates phase transition of a polymer solution at a specific concentration-it passes from the soluble state to the collapsed aggregated state when heated above its lower critical solution temperature (LCST, $\sim 47^{\circ} \mathrm{C}$ at $\mathrm{pH}=7$ and $\sim 35{ }^{\circ} \mathrm{C}$ at $\mathrm{pH}=10$ ), and does not exhibit LCST behavior under acidic 
conditions [49]. Troxerutin-based macromolecules were examined among LCST considering variations in the length of the polymer grafts and polymer concentration (Figure 5). Thermoresponsive behavior of the prepared macromolecules is strictly influenced by both the length of the PDMAEMA side chains, as the concentration of the macromolecules. Star-like polymers with the shortest side chains exhibited LCST at $27.9,28.3$ and $29.2{ }^{\circ} \mathrm{C}$ at concentrations of 3,1 , and $0.5 \mathrm{mg} \mathrm{mL}^{-1}$, respectively. The differences in phase transition temperature changed insignificantly $\left(<1^{\circ} \mathrm{C}\right)$ in different troxerutin-based polymers concentration (Figure 5a). Macromolecules with 73 DMAEMA mers in side chains exhibited notably higher LCST values, i.e., $42.2,42.8$ and $44.4^{\circ} \mathrm{C}$ at polymers concentration of 3,1 , and $0.5 \mathrm{mg} \mathrm{mL}^{-1}$, respectively (Figure $5 \mathrm{~b}$ ). While the molecules with the longest polymer grafts did not show considerable phase transfer at $3 \mathrm{mg} \mathrm{mL}^{-1}$ polymer concentration (transmittance of $56 \%$ at $90^{\circ} \mathrm{C}$ ), and demonstrated LCST at 41.2 and $51.5^{\circ} \mathrm{C}$ at 3 and $1 \mathrm{mg} \mathrm{mL}^{-1}$, respectively (Figure $5 \mathrm{c}$ ). The results indicate the strong correlation between the phase transition temperature and both the length of the polymer grafts and the concentration of macromolecules, indicating high-temperature stability of the prepared macromolecules with the longest PDMAEMA side chains at $0.5 \mathrm{mg} \mathrm{mL}^{-1}$.

(a)

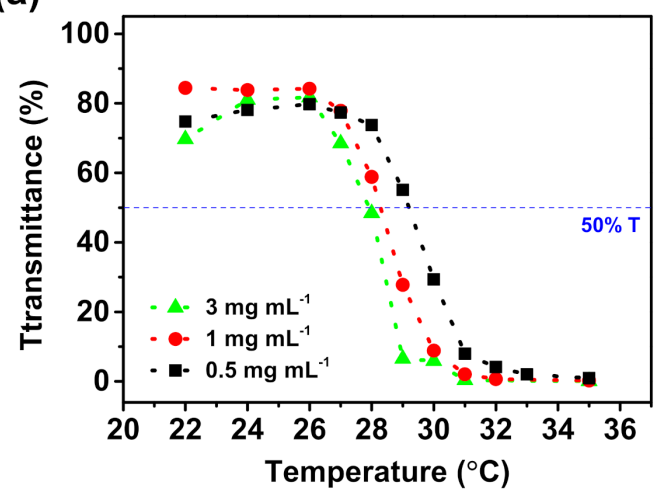

(c)

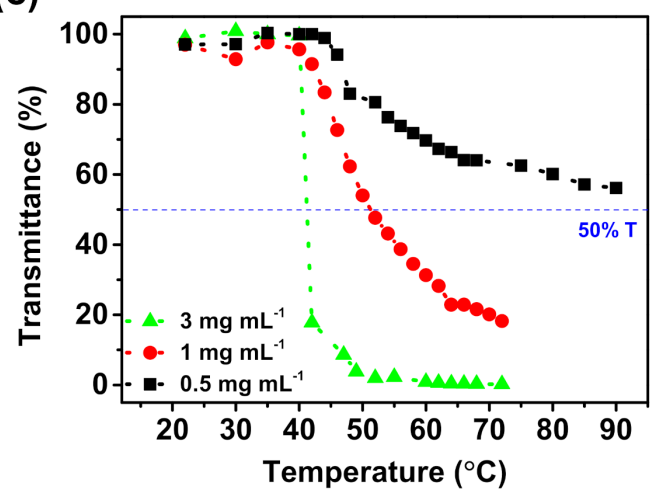

(b)

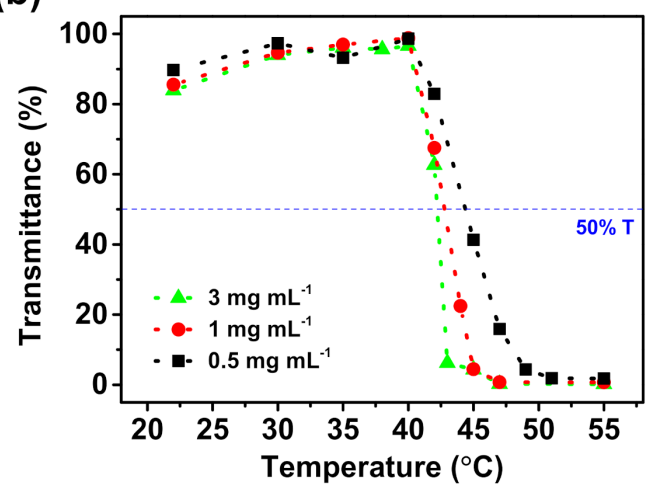

(d)

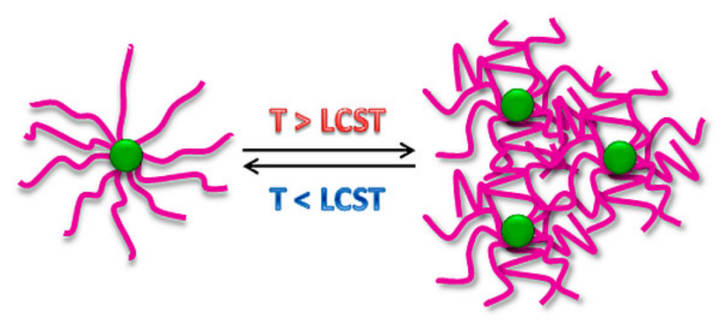

Figure 5. Transmittance at $600 \mathrm{~nm}$ for Trox-(PDMAEMA-Br) 10 with (a) 49, (b) 73, and (c) 98 DMAEMA mers in side chains in aqueous solution with varying concentration; (d) Scheme of thermoresponsive properties of PDMAEMA-based macromolecules with a troxerutin core. The measurements conducted for the final products from the syntheses shown in Table 1, entry 4 and Table S5.

The presented results show that macromolecules with branched architecture are more stable than their linear counterparts. Above LCST temperature, PDMAEMA-based molecules are water-insoluble and considering controlled release systems, they can release substances from the micelle structure, while in an alkaline medium PDMAEMA should effectively entrap the encapsulated substance. High LCST value results in avoiding the unexpected release of the substances when the temperature reached high values, thus, the prepared star-shaped polymers could be an effective smart delivery system with sustained 
release even under harsh temperature conditions, which has a great potential for the use in plants.

\subsection{In Vitro Drug Release}

In view of the $\mathrm{pH}$-responsiveness of the PAA- and PDMAEMA-containing macromolecules, they are capable of a controlled release of an active substance in different $\mathrm{pH}$ values. In acidic conditions, PAA polymers are characterized by a compact globular conformation and are able to encapsulate the substances, while PDMAEMA polymer chains are fully protonated and expanded, thus, the encapsulated compound is released under alkaline conditions.

Quercetin, as a model drug with hydrophobic characteristics, was encapsulated by polymer monomolecular micelles. The mechanism of carrier/drug interaction is covered by the hydrophobic interaction possibly contribute to the compatibility between the drug and carrier. QC is a hydrophobic drug with poor solubility in water $[50,51]$. The prepared polymers are characterized by a unique core-shell architecture, which means the hydrophobic part (troxerutin core) provides a space for the encapsulation of hydrophobic drugs and is surrounded by hydrophilic polymer chains (PAA or PDMAEMA). Polymeric micelles protect the drug (hydrophilic part of micelles), also enabling the delivery of the drug to the desired site at a concentration exceeding the intrinsic solubility, and its sustained release. Considering loading efficiency, PAA-based monomolecular micelles entrapped $85-93 \%$ of QC, varying slightly with the length of the macromolecule side chains. While PDMAEMAbased polymers with shorter side chains entrapped the QC more efficiently (EL $=69$ and $74 \%$ for molecules with the shortest and medium length side chains), the longest side chains entrapped QC two-fold weaker $(\mathrm{EL}=30 \%)$. As the mechanism of the drug encapsulation is based on the hydrophobic interaction between the drug and the core of the macromolecules, access to the hydrophobic core and steric hindrance caused by the hydrophilic shell has paramount importance. The results indicate that the longest PDMAEMA side chains hinder the QC encapsulation, compared to the other two macromolecules-based micelles.

The in vitro release of quercetin was carried out by incubating QC loaded PAA- and PDMAEMA-based monomolecular micelles (Table S9) at $37^{\circ} \mathrm{C}$ in buffers with $\mathrm{pH}$ values of 3.0 and 9.0, respectively. As illustrated in Figure 6, the release of QC from QC-loaded polymer micelles was $\mathrm{pH}$-dependent. However, the release rate did not increase markedly as the $\mathrm{pH}$ changed from 3.0 to 9.0 with increasing lengths of polymer side chains attached to the troxerutin core.

With the increase of the PAA-based side chains of star-shaped polymers, a more visible difference in $\mathrm{QC}$ release in various $\mathrm{pH}$ was noticed. Under alkaline conditions PAA monomolecular micelles formed by macromolecules with homopolymer side chains composed of 40 (Figure 6a), 67 (Figure 6b), and 157 (Figure 6c) AA mers released 25, 31, and $28 \%$ QC after $30 \mathrm{~h}$ of incubation in buffers with different $\mathrm{pH}$ values, respectively. As the length of the side chains increased, only a few percent more quercetin was released. Under acidic conditions, where the QC should be effectively encapsulated, the efficiency of encapsulation was slightly dependent on the PAA side chains. Monomolecular micelles formed from troxerutin-based polymers with $40 \mathrm{AA}$ subunits in side chains inefficiently entrapped QC, $25 \%$ of QC was released. This is the same amount of released active substance as in alkaline conditions. A similar amount of quercetin was released from the medium length and the longest polymer chains, 22 and $24 \%$, respectively. It is merely $8 \%$ and $4 \%$ less than QC release under alkaline conditions. However, compared to the monomolecular micelles created by polymers with the shortest side chains the differences in the active substance release in different $\mathrm{pH}$ were noticed. Therefore, the results show the dependence of the controlled release of QC from PAA-based micelles from the length of polymer grafts. 
(a)

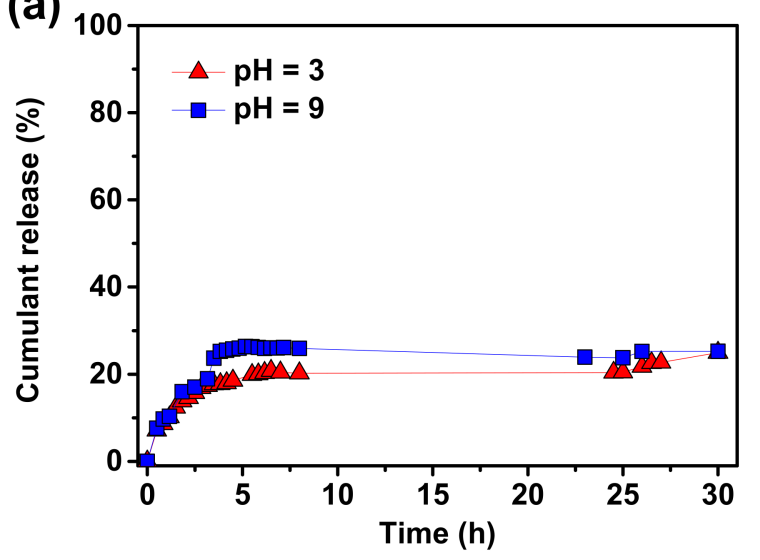

(b)

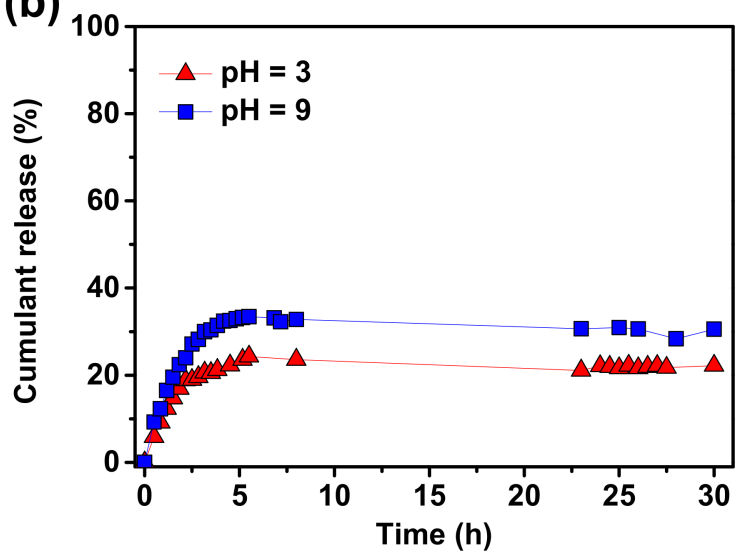

(c)

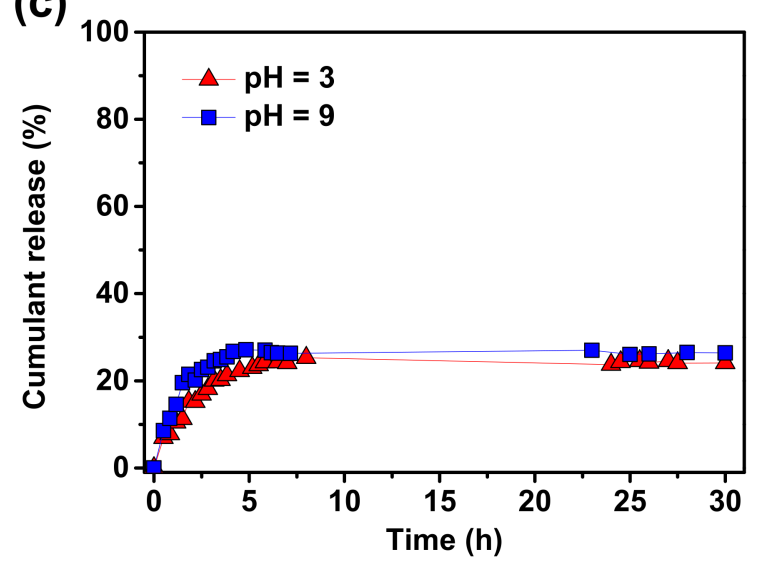

Figure 6. In vitro release profile of quercetin from QC-loaded monomolecular micelles composed of macromolecules with (a) 40, (b) 67, and (c) 157 AA mers in side chains incubated in aqueous solutions at $37^{\circ} \mathrm{C}$. The measurements conducted for the final products from the syntheses shown in Table 1, entry 1-3.

Cumulative release (\%) profiles for the QC-loaded PDMAEMA-based monomolecular micelles composed of polymers with troxerutin core with varying length of side chains were investigated during $7 \mathrm{~h}$ of incubation in buffers with $\mathrm{pH}$ values of 3.0 and $9.0\left(37^{\circ} \mathrm{C}\right)$. PDMAEMA-composed micelles exhibited higher efficiency in the controlled release of QC comparing to PAA composed ones (Figure 7).

The release of QC from QC-loaded monomolecular micelles was $\mathrm{pH}$-dependent, and the release rate increased markedly as the $\mathrm{pH}$ decreased from 9.0 to 3.0, conversely to PAA-based micelles. Additionally, the results indicate that the cumulative QC release $(\%)$ is strictly connected with the length of the polymer grafts, and is significantly higher for the samples with longer PDMAEMA side chains. Under acidic conditions, hydrogen bonds between amino groups are broken, and the PDMAEMA-based molecules exist in a stretched conformation, thus, the release of the active substance is possible. In $\mathrm{pH} 3.0$ the monomolecular micelles formed by star-shaped macromolecules with the shortest side chains $\left(\mathrm{DP}_{\text {per chain }}=49\right)$ released only $12 \%$ of its active substance content, while longer PDMAEMA polymer grafts $\left(\mathrm{DP}_{\text {per chain }}=73\right.$ and 98$)$ released 35 and $83 \%$, respectively. In alkaline medium micelles effectively entrapped QC due to its compact structure resulted from the presence of hydrogen bonds between tertiary amine groups. About 5, 6, and 27\% of the substance was released from the micelles composed from short, medium, and the longest PDMAEMA side chains, respectively. The results showed the great potential of troxerutin-based macromolecules with $\mathrm{pH}$-sensitive grafts in the sustained release of active substances, which can be effectively controlled by selecting the appropriate length of the side chains. 
(a)

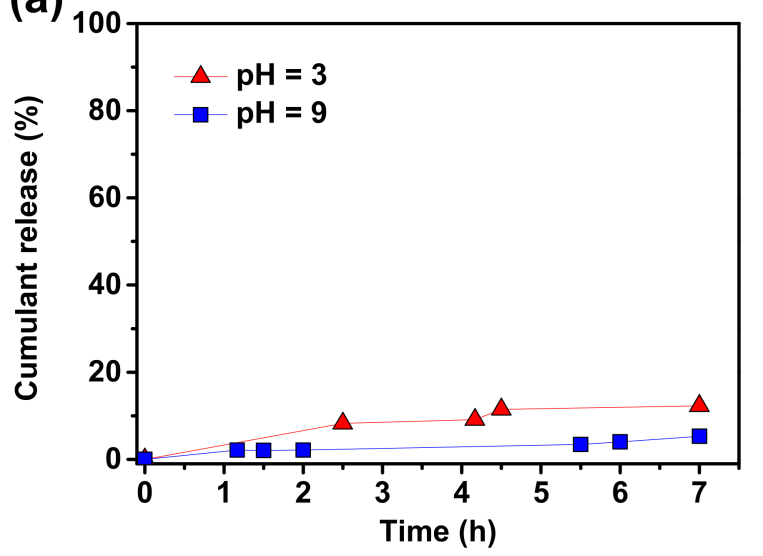

(b)

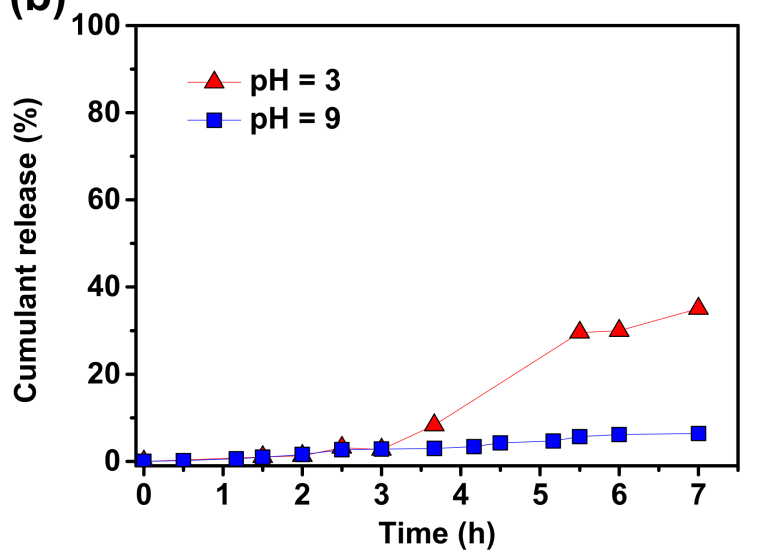

(c)

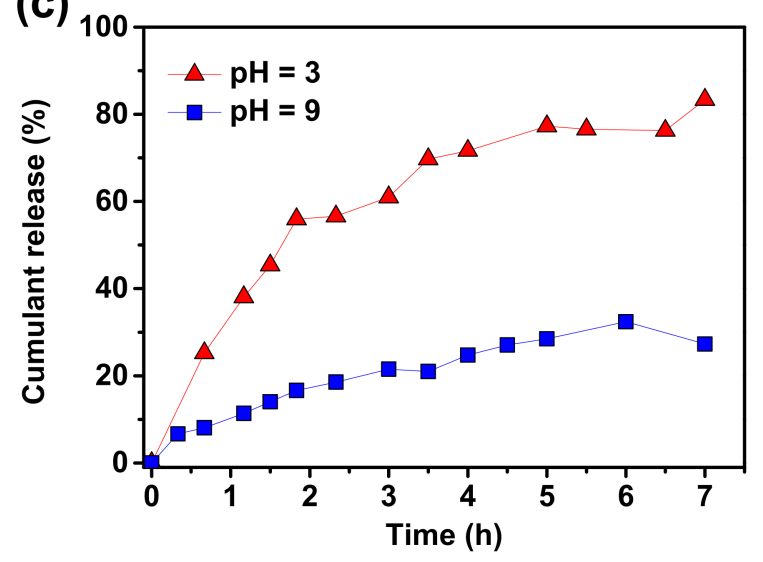

Figure 7. In vitro release profile of quercetin from QC-loaded monomolecular micelles composed of macromolecules with (a) 49, (b) 73, and (c) 98 DMAEMA mers in side chains incubated in aqueous solutions at $37^{\circ} \mathrm{C}$. The measurements conducted for kinetics samples from the synthesis shown in Table 1, entry 4; details in Table S6.

\section{Materials and Methods}

\subsection{Chemicals}

Troxerutin (Trox, $M_{\mathrm{n}}=742.68$, EP Reference Standard), 2-bromoisobutyryl bromide (BriBBr, 98\%), $N$-methyl-2-pyrrolidone (NMP, >99\%), tetrahydrofuran (THF, >99\%), copper(II) bromide $\left(\mathrm{Cu}^{\mathrm{II}} \mathrm{Br}_{2}, 99.9 \%\right)$, dichloromethane (DCM, >99.9\%) and trifluoroacetic acid (TFA, >99\%) were purchased from Sigma Aldrich (Saint Louis, MO, USA). N,NDimethylformamide (DMF, 99.9\%) was purchased from Acros (Fair Lawn, NJ, USA). Deionized water (ACS Reagent) and sodium hydroxide $(\mathrm{NaOH},>98 \%)$ were purchased from Honeywell Riedel-de Haen (Seelze, Germany). These reagents were not subjected to further purification. Tris(2-pyridylmethyl)amine (TPMA) and $\mathrm{Cu}^{\mathrm{II}} \mathrm{Br}_{2}$ /TPMA catalyst complex were prepared as previously reported [35,52]. 2-Dimethylaminoethyl methacrylate (DMAEMA, $>99 \%$, Sigma-Aldrich) and tert-butyl acrylate ( $t$ BA, $>99 \%$, Sigma-Aldrich) were passed through a column filled with basic alumina before use in order to remove inhibitor [53]. $\mathrm{Cu}^{0}$ wire was purchased from Alfa Aesar (99.9\%, Tewksbury, MA, USA).

\subsection{Analysis}

Proton nuclear magnetic resonance $\left({ }^{1} \mathrm{H}\right.$ NMR) spectra were carried out in $\mathrm{CDCl}_{3}$ using Bruker Avance $500 \mathrm{MHz}$ spectrometer (Bruker, Karlsruhe, Germany) in $25^{\circ} \mathrm{C}$. Numberaverage molecular weight $\left(M_{n}\right)$ and molecular weight distribution $\left(M_{\mathrm{w}} / M_{\mathrm{n}}\right)$ were measured by size exclusion chromatography GPC using a Shimadzu (Kyoto, Japan) modular system equipped with a CBM-40 system controller, SIL-20AHT automatic injector, two 
Repro-Gel GPC $5 \mu \mathrm{m}$ columns (10,000 and 100,000 ̊̊) and RID-20A differential refractiveindex detector. The temperature of the columns was maintained at $30^{\circ} \mathrm{C}$ using a CTO-20A oven. The eluent was $\mathrm{N}, \mathrm{N}$-dimethylformamide (HPLC grade, with $0.05 \mathrm{M} \mathrm{LiCl}$ ) and the flow rate was kept at $1 \mathrm{~mL} \mathrm{~min}{ }^{-1}$ using an LC-40 pump. A molecular weight calibration curve was produced using commercial narrow molecular weight distribution polystyrene standards (PSS Polymer Standards Service, Mainz, Germany). Number mean diameter $\left(d_{\text {number }}\right)$ of polymer sample $(5 \mathrm{mg} / \mathrm{mL}$ in THF or water) and zeta potential was measured by dynamic light scattering (DLS, Zetasizer Nano ZS, Malvern Panalytical, Worcestershire, UK) at $22{ }^{\circ} \mathrm{C}$. The UV-VIS spectra were obtained on a Hewlett-Packard (Waldbronn, Germany) Model HP-8453 diode array rapid scan spectrophotometer using a quartz cell with optical length of $1 \mathrm{~cm}$. FT-IR analyses were conducted with the spectrophotometer Nicolet 6700 FT-IR (Thermo Scientific, Waltham, MA, USA), within $500-4000 \mathrm{~cm}^{-1}$, with the use of attenuated total reflectance (ATR) technique.

\subsection{Synthesis of Troxerutin-Based Macroinitiator (Trox-Br ${ }_{10}$ )}

Troxerutin-based ATRP macroinitiator was prepared according to the previous published procedure [35] as follows: troxerutin $(1 \mathrm{~g}, 1.35 \mathrm{mmol})$ was dissolved in NMP $(20 \mathrm{~mL})$ under Ar atmosphere in $50 \mathrm{~mL}$ round-bottom flask equipped with $25 \mathrm{~mL}$ cylindrical separatory funnel filled with a solution of $\operatorname{BriBBr}(4.99 \mathrm{~mL}, 40.4 \mathrm{mmol}$, four-fold molar excess to each troxerutin hydroxyl group) in NMP $(12.0 \mathrm{~mL})$. A solution was added dropwise over a period of 1 hour at $0{ }^{\circ} \mathrm{C}$, and the reaction mixture was stirred for seven days at room temperature. The reaction mixture was dissolved in $40 \mathrm{~mL}$ dichloromethane and washed with $60 \mathrm{~mL}$ water $(1 \times)$ and $60 \mathrm{~mL}$ sodium bicarbonate $(6 \times)$. The product was dialyzed against water six times using a molecular cut-off membrane (MWCO 1000) for 14 days. Then water was removed under pressure and the resulting brown powder was dried over $24 \mathrm{~h}$ under vacuum (53.9 $\mathrm{mg}$, yield $35.9 \%$ ).

\subsection{General Procedure for $S A R A$ ATRP of $t B A$ from $T r o x-B r_{10}$}

The mixture of $t \mathrm{BA}(3.00 \mathrm{~mL}, 20.5 \mathrm{mmol}), \mathrm{Cu}^{\mathrm{II}} \mathrm{Br}_{2} / \mathrm{TPMA}$ stock solution $(123 \mu \mathrm{L}$ of $0.05 \mathrm{M}$ in DMF), Trox-Br 10 (91.5 mg, $4.1 \mathrm{mmol}$ or $45.7 \mathrm{mg}, 2.0 \mathrm{mmol}$, or $22.9 \mathrm{mg}, 1.0 \mathrm{mmol}$ ) and DMF $(5.88 \mathrm{~mL})$ was added to a $10 \mathrm{~mL}$ Schlenck flask equipped with a magnetic stirrer bar. Next, $\mathrm{Cu}^{0}$ wire (dimension $=10 \mathrm{~cm}$ length; thickness $1 \mathrm{~mm}$ ) previously activated with $\mathrm{HCl}$ and washed with THF was placed in a rubber septum that was placed in a Schlenck flask containing reaction mixture. The mixture was degassed for 15 min under argon atmosphere. The flask was placed in an oil bath heated to $50{ }^{\circ} \mathrm{C}$. The polymerization reaction was initiated after adding $\mathrm{Cu}^{0}$ wire to the reaction mixture. Samples were withdrawn periodically to follow monomer conversion using ${ }^{1} \mathrm{H}$ NMR analysis, and to check $M_{n}$ and $M_{\mathrm{w}} / M_{\mathrm{n}}$ of the polymers by GPC analysis. Before GPC analysis the polymer samples were dissolved in $\mathrm{DMF}+0.05 \mathrm{M} \mathrm{LiCl}+$ toluene as external standard mobile phase, and passed through a neutral alumina column with $0.22 \mu \mathrm{m}$ syringe filter in order to remove the catalyst. The polymerization was stopped by opening the flask and exposing the catalyst to air after $\mathrm{t}=3.25 \mathrm{~h}$ (Table 1 , entry 1$), \mathrm{t}=2.17 \mathrm{~h}$ (Table 1 , entry 2), and $\mathrm{t}=2.25 \mathrm{~h}$ (Table 1 , entry 3). The final polymer product was purified by precipitation against $\mathrm{MeOH}$ and dried under vacuum, and analyzed by ${ }^{1} \mathrm{H}$ NMR.

\subsection{Transformation of $P \mathrm{t} B A$ to $P A A$ Side Chains}

The PtBA moieties of troxerutin-based macromolecules were hydrolyzed to PAA blocks as previously reported [5]. The final sample was characterized by ${ }^{1} \mathrm{H}$ NMR and FT-IR analysis.

\subsection{General Procedure for $S A R A$ ATRP of DMAEMA from Trox-Br $r_{10}$}

The mixture of DMAEMA (6.00 mL, $17.8 \mathrm{mmol}), \mathrm{Cu}^{\mathrm{II}} \mathrm{Br}_{2} /$ TPMA stock solution $(0,499$ $\mu \mathrm{L}$ of $0.05 \mathrm{M}$ in DMF), $\operatorname{Trox}_{-\mathrm{Br}_{10}}(10 \mathrm{mg}, 2.0 \mathrm{mmol})$, and $\mathrm{DMF}(13.50 \mathrm{~mL})$ was added to 20 $\mathrm{mL}$ Schlenck flask equipped with a magnetic stirrer bar. Then, $\mathrm{Cu}^{0}$ wire $(l=20 \mathrm{~cm}, d=1$ 
$\mathrm{mm}$ ) previously activated with $\mathrm{HCl}$ and washed with THF was placed in a rubber septum that was placed in a Schlenck flask containing the reaction mixture. The mixture was degassed for $25 \mathrm{~min}$ under an argon atmosphere. The flask was placed in an oil bath heated to $50{ }^{\circ} \mathrm{C} . \mathrm{Cu}^{0}$ wire was added to the reaction flask to start the reaction polymerization. Samples were withdrawn periodically to follow the monomer conversion, using ${ }^{1} \mathrm{H}$ NMR. The molecular weight and molecular weight distribution of the polymers were measured by size exclusion chromatography (SEC). To receive three kinetics samples, three syntheses were conducted in the same reaction conditions stopping the polymerizations after 1, 3, and $5 \mathrm{~min}$. The polymerization was stopped by opening the flask and exposing the catalyst to air. The polymer products were purified by dialysis against water and dried under vacuum, and analyzed by ${ }^{1} \mathrm{H}$ NMR.

\subsection{Determination of $\mathrm{pH}$-sensitivity of PAA- and PDMAEMA-Based Polymers}

The behavior of the troxerutin-based macromolecules with PAA side chains against $\mathrm{pH}$ changes was investigated by potentiometric titration, determining the hydrodynamic radius of polymers and zeta potential by DLS measurements of the polymer solutions in different $\mathrm{pH}$ values at $22^{\circ} \mathrm{C}$. Potentiometric titration was performed using a digital $\mathrm{pH}$ meter (CPC-551, ELMETRON, Zabrze, Poland) equipped with a combined glass/reference electrode (ERH-13-6, HYDROMET, Gliwice, Poland). The PAA-based polymer was dissolved in $0.1 \mathrm{M} \mathrm{NaOH}(3 \mathrm{mg} / \mathrm{mL}$ solution). The value of $\mathrm{pH}$ was adjusted by titration with aqueous $0.1 \mathrm{M} \mathrm{HCl}$ under intensive stirring, at a constant temperature $\left(22^{\circ} \mathrm{C}\right)$. While PDMAEMA-based polymer was dissolved in $0.1 \mathrm{M} \mathrm{HCl}$ and the value of $\mathrm{pH}$ was adjusted by titration with aqueous $0.1 \mathrm{M} \mathrm{NaOH}$ under intensive stirring, at a constant temperature $\left(22{ }^{\circ} \mathrm{C}\right) \cdot \mathrm{pH}$ readings were registered after each portion of titrant added to the polymer solution when the equilibrium state was established and the polymer sample was analyzed by DLS measurement.

\subsection{Determination of Thermoresponsive Behavior of PDMAEMA-Based Polymers}

Thermoresponsive behavior of the troxerutin-based macromolecules with DMAEMA side chains was investigated by measurements of transmittances (UV-VIS measurements) of the polymer aqueous solutions (carbonate buffer $\mathrm{pH}=9$ ) at various temperatures and different polymer concentration. Transmittances were measured at a wavelength of 600 $\mathrm{nm}$, and the lower critical solution temperature (LCST) value of the lignin-based polymer solution was defined as the temperature producing a 50\% decrease in transmittance.

\subsection{Loading of Quercetin into the PAA- and PDMAEMA-Based Polymer and Release Behavior upon $\mathrm{pH}$ Changes}

Quercetin loaded micelles were prepared by the dialysis method namely, $20 \mathrm{mg}$ of troxerutin-based polymer and $8 \mathrm{mg}$ of QC was dissolved in $5 \mathrm{~mL}$ DMF separately, stirred for half an hour and then mixed and stirred for half an hour. The mixed solution was added dropwise into $10 \mathrm{~mL}$ water and stirred for $1.5 \mathrm{~h}$. The prepared micelle solution was placed in a dialysis membrane (Spectra/Por dialysis membrane, MWCO 1000) and dialyzed against deionized water for some cycles over seven days. The received QC loaded micelles solution was adjusted to $60 \mathrm{~mL}$ by DMF or water, and the total mass of QC loaded in PAA-based micelles was estimated on the basis of the calibration curve of the absorption intensity at $\lambda=374 \mathrm{~nm}$ as a function of QC concentration in DMF. The loading efficiency (EL) was calculated as follows:

$$
\mathrm{EL}(\mathrm{wt} . \%)=\frac{\mathrm{w}_{\mathrm{p}}}{\mathrm{w}_{\mathrm{t}}} \times 100 \%
$$

where $\mathrm{w}_{\mathrm{p}}$ and $\mathrm{w}_{\mathrm{t}}$ are the mas of $\mathrm{QC}$ in micelles and total $\mathrm{QC}$ used in the preparation of micelles, respectively (Table S9).

To investigate the release of an active substance loaded in PAA- or PDMAEMAbased micelles $20 \mathrm{~mL}$ of $\mathrm{QC}$ loaded micelle solution was placed into a dialysis membrane 
(Spectra/Por dialysis membrane, MWCO 1000) and immersed into $300 \mathrm{~mL}$ of buffer solution (citrate-phosphate buffer $\mathrm{pH}=3$ and carbonate buffer $\mathrm{pH}=9$ ). The solutions were incubated at $37^{\circ} \mathrm{C}$. The samples were withdrawn periodically $1 \mathrm{~mL}$ and replaced by $1 \mathrm{~mL}$ of water. The concentration of released QC was investigated on the basis of UV-VIS spectra based on calibration curves of the absorption intensity at $\lambda=366(\mathrm{pH}=3)$ and $\lambda=320$ $(\mathrm{pH}=9)$ as a function of QC concentration in an appropriate buffer.

\section{Conclusions}

Precisely-defined polyelectrolytes with troxerutin core and ten PAA or PDMAEMA arms were synthesized by SARA ATRP approach using metallic copper as a reducing agent. PAA-based polymers were formed by acidolysis of PtBA moieties, and the structure was successfully confirmed by ${ }^{1} \mathrm{H}$ NMR and FT-IR analysis. The prepared macromolecules were characterized by narrow molecular weight distribution: $M_{\mathrm{w}} / M_{\mathrm{n}}=1.05-1.09$ and $M_{\mathrm{w}} / M_{\mathrm{n}}=1.15-1.71$ for PtBA and PDMAEMA-based polymers, respectively. Dynamic light scattering measurements demonstrate the $\mathrm{pH}$-responsive behavior of both PAA and PDMAEMA composed star-shaped polymers. In acidic conditions, Trox-(PAA-Br $)_{10}$ molecules were agglomerated, and the generated dispersion was rapidly and macroscopically precipitated, resulting in a significant increase in the diameter of nanoparticles (from $d_{\text {number }} \sim 13 \mathrm{~nm}$ to $d_{\text {number }} \sim 5500 \mathrm{~nm}$ ), while in alkaline medium the polymers were fully soluble in aqueous solution. PDMAEMA-based monomolecular micelles exhibited fully expanded polymer chains in acidic $\mathrm{pH}$, thus, the highest hydrodynamic radius. With the increase of $\mathrm{pH}$ value, the polymers were stretched and the hydrodynamic radius was decreased, without forming the aggregates.

The in vitro release of quercetin was carried out by incubating QC loaded PAA- and PDMAEMA-based monomolecular micelles at $37^{\circ} \mathrm{C}$ in buffers with $\mathrm{pH}$ values of 3.0 and 9.0, respectively. The release of QC from QC-loaded polymer micelles was $\mathrm{pH}$-dependent and was more efficient with longer polymer grafts. Considering PAA-based monomolecular micelles, the polymer grafts length has an inconsiderable influence on release efficiency. However, polymer micelles composed of molecules with the longest side chains more efficiently entrapped QC inside. While cumulative QC release (\%) from PDMAEMA-based monomolecular micelles was more efficient and was strictly connected with the length of the polymer grafts, the micelles with the longest polymer grafts efficiently released $83 \%$ of QC in acidic conditions, and entrapped the substance in alkaline solutions, releasing only $35 \%$ of QC. Additionally, the LCST value of PDMAEMA star-shaped polymers was higher than in their linear counterparts presented in the literature, thus, the received polymers are able to efficiently entrapped the substances even at harsh temperature conditions, and have excellent potential for use as a smart delivery system in plants. The results showed the great potential of troxerutin-based macromolecules with $\mathrm{pH}$-sensitive grafts in sustained release of active substances, which can be effectively controlled by selecting the appropriate length of the side chains in both human organism and plants. The star-like polymers with PAA side chains due to a fully biocompatible both troxerutin core and acrylic acid-based grafts have a great potential for the use in human organism for smart site-specific delivery of drug and active substances. While PDMAEMA exhibits toxicity on healthy living cells, thus it can be used as smart materials with agrochemical use to efficiently release pesticide, fungicide, and micronutrients, and avoid the damage of plant by acid rains or a large amount of plant protection products that are washed off the leaves.

Supplementary Materials: The following are available online, Figure S1. GPC traces of Trox$(\mathrm{P} t \mathrm{BA}-\mathrm{Br})_{10}$ polymer samples withdrawn periodically during polymerization with $\mathrm{DP}_{\text {target }}=50$ : (a) High-molecular weight (HMW) fraction of Trox-(PtBA-Br $)_{10}$ and (b) with an additional lowmolecular weight (LMW) fraction formed during the polymerization, Figure S2. GPC traces of Trox$(\mathrm{P} t \mathrm{BA}-\mathrm{Br})_{10}$ polymer samples withdrawn periodically during polymerization with $\mathrm{DP}_{\text {target }}=100$ : (a) High-molecular weight (HMW) fraction of Trox-(PtBA-Br) $)_{10}$ and (b) with an additional lowmolecular weight (LMW) fraction formed during the polymerization, Figure S3. GPC traces of Trox$(\mathrm{P} t \mathrm{BA}-\mathrm{Br})_{10}$ polymer samples withdrawn periodically during polymerization with $\mathrm{DP}_{\text {target }}=200$ : 
(a) high-molecular weight (HMW) fraction of Trox-(PtBA-Br) 10 and (b) with an additional lowmolecular weight (LMW) fraction formed during the polymerization, Figure S4. GPC traces of Trox-(PDMAEMA-Br) 10 kinetics polymer samples, Figure S5. ${ }^{1} \mathrm{H}$ NMR spectrum of macromolecules with a troxerutin core and PtBA side chains (Table 1, entry $3 ; M_{\mathrm{n}}=203,300, M_{\mathrm{w}} / M_{\mathrm{n}}=1.09$ ) after purification (in $\mathrm{CDCl}_{3}$ ), Figure S6. ${ }^{1} \mathrm{H}$ NMR spectrum of macromolecules with troxerutin core and PAA side chains received as a result of acidolysis of $t$ BA moieties (Table 1 , entry $3 ; M_{n}=203,300$, $M_{\mathrm{w}} / M_{\mathrm{n}}=1.09$ ) after purification (in $\mathrm{CDCl}_{3}$ ), Figure S7. ${ }^{1} \mathrm{H}$ NMR spectrum of macromolecules with troxerutin core and PDMAEMA side chains (Table 1 , entry $3 ; M_{\mathrm{n}}=203,300, M_{\mathrm{w}} / M_{\mathrm{n}}=1.09$ ) after purification (in $\mathrm{CDCl}_{3}$ ), Figure S8. FT-IR spectra of troxerutin modified with bromine (ATRP macroinitiator), PtBA (Table 1, entry 3), PAA (hydrolyzed, Table 1, entry 3) and PDMAEMA (Table 1, entry 4), Figure S9. DLS analysis of PtBA (a), (c), (e) and corresponding PAA (b), (d), (f) received in the polymerization with the $\mathrm{DP}_{\text {target }}=50$ (Table 1, entry 1), 100 (Table 1, entry 2) and 200 (Table 1, entry 3), respectively, Figure S10. DLS analysis of PDMAEMA-based macromolecules with side chains composed of (a) 49 (Table S6, entry 1), (b) 73 (Table S6, entry 2), and (c) 98 (Table 1, entry 4, Table S6, entry 3) DMAEMA subunits, Table S1. Calculation of $\mathrm{Cu}^{\mathrm{I}} / \mathrm{Cu}^{\mathrm{II}}$ ratio for the preparation of troxerutin-based macromolecules, Table S2. Calculation of theoretical dead chain fraction $\left(\mathrm{DCF}_{\text {theo }}\right)$ for polymerization of (meth)acrylates via SARA ATRP approach, Table S3. Low-molecular weight (LMW) fraction in the samples withdrawn periodically during polymerization of $t \mathrm{BA}$ from $\operatorname{Trox}-\mathrm{Br}_{10}$ with $\mathrm{DP}_{\text {target }}=50$, Table S4. Low-molecular weight (LMW) fraction in the samples withdrawn periodically during polymerization of $t \mathrm{BA}$ from Trox-Br 10 with $\mathrm{DP}_{\text {target }}=100$, Table S5. Low-molecular weight $(\mathrm{LMW})$ fraction in the samples withdrawn periodically during polymerization of $t \mathrm{BA}$ from Trox- $\mathrm{Br}_{10}$ with $\mathrm{DP}_{\text {target }}=100$, Table S6. Kinetics polymer samples of DMAEMA polymerization from Trox- $\mathrm{Br}_{10}$, Table S7. Number of the mean diameter of PAA-based macromolecules at varying $\mathrm{pH}$, Table S8. Number of the mean diameter of PDMAEMA-based macromolecules at varying $\mathrm{pH}$. References $[5,28,35,45,53]$ are cited in the supplementary materials.

Author Contributions: Conceptualization: P.C.; data curation: I.Z., and P.C.; formal analysis: P.C., and I.Z.; funding acquisition: P.C.; investigation: I.Z., and A.M; methodology: P.C., and I.Z.; project administration: P.C.; resources: P.C.; supervision: P.C.; validation: I.Z., A.M., and P.C.; visualization: I.Z. and P.C.; writing-original draft: I.Z. and P.C.; writing-review and editing: I.Z. and P.C. All authors have read and agreed to the published version of the manuscript.

Funding: Financial support from UPB.CF.20.001.01 and BK/RDKN/2020/01 is gratefully acknowledged. P.C. acknowledges Minister of Science and Higher Education scholarship for outstanding young scientists (0001/E-363/STYP/13/2018). I.Z. acknowledges National Science Centre in Poland for the financial support as a part of the PRELUDIUM 19 project (2020/37/N/ST4/01991).

Institutional Review Board Statement: Not applicable.

Informed Consent Statement: Not applicable.

Data Availability Statement: The data presented in this study are available on request from the corresponding author.

Acknowledgments: We would like to thank the Laboratory of Spectrometry (Faculty of Chemistry, Rzeszow University of Technology) for conducting NMR analyses.

Conflicts of Interest: The authors declare no conflict of interest.

Sample Availability: Samples of the compounds presented in the paper are available on request from the corresponding author.

\section{References}

1. Hunter, A.C.; Moghimi, S.M. Smart polymers in drug delivery: A biological perspective. Polym. Chem. 2017, 8, 41-51. [CrossRef]

2. Wells, C.M.; Harris, M.; Choi, L.; Murali, V.P.; Guerra, F.D.; Jennings, J.A. Stimuli-responsive drug release from smart polymers. J. Funct. Biomater. 2019, 10, 34. [CrossRef]

3. Sponchioni, M.; Capasso Palmiero, U.; Moscatelli, D. Thermo-responsive polymers: Applications of smart materials in drug delivery and tissue engineering. Mater. Sci. Eng. C 2019, 102, 589-605. [CrossRef] [PubMed]

4. Zhang, Y.; Yan, J.; Avellan, A.; Gao, X.; Matyjaszewski, K.; Tilton, R.D.; Lowry, G.V. Temperature- and pH-responsive star polymers as nanocarriers with potential for in vivo agrochemical delivery. ACS Nano 2020, 14, 10954-10965. [CrossRef]

5. Zaborniak, I.; Macior, A.; Chmielarz, P. Stimuli-responsive rifampicin-based macromolecules. Materials 2020, 13, 3843. [CrossRef] 
6. Pack, D.W.; Hoffman, A.S.; Pun, S.; Stayton, P.S. Design and development of polymers for gene delivery. Nat. Rev. Drug Discov. 2005, 4, 581-593. [CrossRef] [PubMed]

7. Xiang, Y.G.; Oo, N.N.L.; Lee, J.P.; Li, Z.B.; Loh, X.J. Recent development of synthetic nonviral systems for sustained gene delivery. Drug Discov. Today 2017, 22, 1318-1335. [CrossRef] [PubMed]

8. Jabbarzadeh, A.; Atkinson, J.D.; Tanner, R.I. Effect of molecular shape on rheological properties in molecular dynamics simulation of star, H, comb, and linear polymer melts. Macromolecules 2003, 36, 5020-5031. [CrossRef]

9. Xu, J.; Ge, Z.; Zhu, Z.; Luo, S.; Liu, H.; Liu, S. Synthesis and micellization properties of double hydrophilic $\mathrm{A}_{2} \mathrm{BA}_{2}$ and $\mathrm{A}_{4} \mathrm{BA}_{4}$ non-linear block copolymers. Macromolecules 2006, 39, 8178-8185. [CrossRef]

10. Ge, Z.; Cai, Y.; Yin, J.; Zhu, Z.; Rao, J.; Liu, S. Synthesis and 'schizophrenic' micellization of double hydrophilic $\mathrm{AB}_{4}$ miktoarm star and ab diblock copolymers: Structure and kinetics of micellization. Langmuir 2007, 23, 1114-1122. [CrossRef]

11. Jiang, X.; Lu, G.; Feng, C.; Li, Y.; Huang, X. Poly(acrylic acid)-graft-poly(N-vinylcaprolactam): A novel pH and thermo dual-stimuli responsive system. Polym. Chem. 2013, 4, 3876-3884. [CrossRef]

12. Wang, Q.; Zhang, J.; Wang, A. Preparation and characterization of a novel pH-sensitive chitosan-g-poly (acrylic acid)/attapulgite/ sodium alginate composite hydrogel bead for controlled release of diclofenac sodium. Carbohydr. Polym. 2009, 78, 731-737. [CrossRef]

13. Hu, X.; Wei, W.; Qi, X.; Yu, H.; Feng, L.; Li, J.; Wang, S.; Zhang, J.; Dong, W. Preparation and characterization of a novel pH-sensitive Salecan-g-poly(acrylic acid) hydrogel for controlled release of doxorubicin. J. Mater. Chem. B 2015, 3, 2685-2697. [CrossRef]

14. Xu, M.; Zhu, J.; Wang, F.; Xiong, Y.; Wu, Y.; Wang, Q.; Weng, J.; Zhang, Z.; Chen, W.; Liu, S. Improved in vitro and in vivo biocompatibility of graphene oxide through surface modification: Poly(acrylic acid)-functionalization is superior to PEGylation. ACS Nano 2016, 10, 3267-3281. [CrossRef] [PubMed]

15. Wang, Z.-C.; Xu, X.-D.; Chen, C.-S.; Wang, G.-R.; Wang, B.; Zhang, X.-Z.; Zhuo, R.-X. Study on novel hydrogels based on thermosensitive PNIPAAm with pH sensitive PDMAEMA grafts. Colloids Surf. B 2008, 67, 245-252. [CrossRef]

16. Zhou, Z.; Guo, F.; Wang, N.; Meng, M.; Li, G. Dual pH-sensitive supramolecular micelles from star-shaped PDMAEMA based on $\beta$-cyclodextrin for drug release. Int. J. Biol. Macromol. 2018, 116, 911-919. [CrossRef] [PubMed]

17. Zou, H.; Yuan, W. $\mathrm{CO}_{2}$ - and thermo-responsive vesicles: From expansion-contraction transformation to vesicles-micelles transition. Polym. Chem. 2015, 6, 2457-2465. [CrossRef]

18. Bonkovoski, L.C.; Martins, A.F.; Bellettini, I.C.; Garcia, F.P.; Nakamura, C.V.; Rubira, A.F.; Muniz, E.C. Polyelectrolyte complexes of poly[(2-dimethylamino) ethyl methacrylate]/chondroitin sulfate obtained at different pHs: Preparation, characterization, cytotoxicity and controlled release of chondroitin sulfate. J. Control. Release 2015, 213, e29-e30. [CrossRef]

19. Ferjaoui, Z.; Jamal Al Dine, E.; Kulmukhamedova, A.; Bezdetnaya, L.; Soon Chang, C.; Schneider, R.; Mutelet, F.; Mertz, D.; Begin-Colin, S.; Quilès, F.; et al. Doxorubicin-loaded thermoresponsive superparamagnetic nanocarriers for controlled drug delivery and magnetic hyperthermia applications. ACS Appl. Mater. Interfaces 2019, 11, 30610-30620. [CrossRef]

20. Almeida, E.A.M.S.; Bellettini, I.C.; Garcia, F.P.; Farinácio, M.T.; Nakamura, C.V.; Rubira, A.F.; Martins, A.F.; Muniz, E.C. Curcuminloaded dual $\mathrm{pH}$ - and thermo-responsive magnetic microcarriers based on pectin maleate for drug delivery. Carbohydr. Polym. 2017, 171, 259-266. [CrossRef]

21. Huang, B.; Chen, F.; Shen, Y.; Qian, K.; Wang, Y.; Sun, C.; Zhao, X.; Cui, B.; Gao, F.; Zeng, Z.; et al. Advances in targeted pesticides with environmentally responsive controlled release by nanotechnology. Nanomaterials 2018, 8, 102. [CrossRef] [PubMed]

22. Mann, M.; Kruger, J.E.; Andari, F.; McErlean, J.; Gascooke, J.R.; Smith, J.A.; Worthington, M.J.H.; McKinley, C.C.C.; Campbell, J.A.; Lewis, D.A.; et al. Sulfur polymer composites as controlled-release fertilisers. Org. Biomol. Chem. 2019, 17, 1929-1936. [CrossRef]

23. Siegwart, D.J.; Oh, J.K.; Matyjaszewski, K. ATRP in the design of functional materials for biomedical applications. Prog. Polym. Sci. 2012, 37, 18-37. [CrossRef]

24. Matyjaszewski, K. Advanced materials by atom transfer radical polymerization. Adv. Mater. 2018, 30, 1706441. [CrossRef]

25. Zaborniak, I.; Chmielarz, P.; Matyjaszewski, K. Modification of wood-based materials by atom transfer radical polymerization methods. Eur. Polym. J. 2019, 120, 109253. [CrossRef]

26. Zaborniak, I.; Chmielarz, P.; Matyjaszewski, K. Synthesis of riboflavin-based macromolecules through low ppm ATRP in aqueous media. Macromol. Chem. Phys. 2020, 221, 1900496. [CrossRef]

27. Corrigan, N.; Jung, K.; Moad, G.; Hawker, C.J.; Matyjaszewski, K.; Boyer, C. Reversible-deactivation radical polymerization (Controlled/living radical polymerization): From discovery to materials design and applications. Prog. Polym. Sci. 2020, 111, 101311. [CrossRef]

28. Park, S.; Chmielarz, P.; Gennaro, A.; Matyjaszewski, K. Simplified electrochemically mediated atom transfer radical polymerization using a sacrificial anode. Angew. Chem. Int. Ed. 2015, 54, 2388-2392. [CrossRef]

29. Beers, K.L. The first dive into the mechanism and kinetics of ATRP. Macromolecules 2020, 53, 1115-1118. [CrossRef]

30. Lorandi, F.; Matyjaszewski, K. Why do we need more active ATRP catalysts? Isr. J. Chem. 2020, 60, 108-123. [CrossRef]

31. Doerr, A.M.; Burroughs, J.M.; Gitter, S.R.; Yang, X.; Boydston, A.J.; Long, B.K. Advances in polymerizations modulated by external stimuli. ACS Catal. 2020, 10, 14457-14515. [CrossRef]

32. Chmielarz, P.; Park, S.; Sobkowiak, A.; Matyjaszewski, K. Synthesis of $\beta$-cyclodextrin-based star polymers via a simplified electrochemically mediated ATRP. Polymer 2016, 88, 36-42. [CrossRef] 
33. Li, R.; Li, X.; Zhang, Y.; Delawder, A.O.; Colley, N.D.; Whiting, E.A.; Barnes, J.C. Diblock brush-arm star copolymers via a core-first/graft-from approach using $\gamma$-cyclodextrin and ROMP: A modular platform for drug delivery. Polym. Chem. 2020, 11, 541-550. [CrossRef]

34. Zaborniak, I.; Chmielarz, P.; Martinez, M.R.; Wolski, K.; Wang, Z.; Matyjaszewski, K. Synthesis of high molecular weight poly(n-butyl acrylate) macromolecules via seATRP: From polymer stars to molecular bottlebrushes. Eur. Polym. J. 2020, 126, 109566. [CrossRef]

35. Zaborniak, I.; Chmielarz, P. Miniemulsion switchable electrolysis under constant current conditions. Polym. Adv. Technol. 2020, 31, 2806-2815. [CrossRef]

36. Vinothkumar, R.; Kumar, R.V.; Sudha, M.; Viswanathan, P.; Balasubramanian, T.; Nalini, N. Modulatory effect of troxerutin on biotransforming enzymes and preneoplasic lesions induced by 1,2-dimethylhydrazine in rat colon carcinogenesis. Exp. Mol. Pathol. 2014, 96, 15-26. [CrossRef] [PubMed]

37. Panat, N.A.; Singh, B.G.; Maurya, D.K.; Sandur, S.K.; Ghaskadbi, S.S. Troxerutin, a natural flavonoid binds to DNA minor groove and enhances cancer cell killing in response to radiation. Chem. Biol. Interact. 2016, 251, 34-44. [CrossRef] [PubMed]

38. Chmielarz, P. Synthesis of $\alpha$-D-glucose-based star polymers through simplified electrochemically mediated ATRP. Polymer 2016, 102, 192-198. [CrossRef]

39. Chmielarz, P.; Krys, P.; Park, S.; Matyjaszewski, K. PEO- $b$-PNIPAM copolymers via SARA ATRP and $e$ ATRP in aqueous media. Polymer 2015, 71, 143-147. [CrossRef]

40. Chmielarz, P.; Sobkowiak, A.; Matyjaszewski, K. A simplified electrochemically mediated ATRP synthesis of PEO- $b$-PMMA copolymers. Polymer 2015, 77, 266-271. [CrossRef]

41. Laguecir, A.; Ulrich, S.; Labille, J.; Fatin-Rouge, N.; Stoll, S.; Buffle, J. Size and pH effect on electrical and conformational behavior of poly(acrylic acid): Simulation and experiment. Eur. Polym. J. 2006, 42, 1135-1144. [CrossRef]

42. Zhang, L.; Eisenberg, A. Multiple morphologies and characteristics of "crew-cut" micelle-like aggregates of polystyrene- $b$ poly(acrylic acid) diblock copolymers in aqueous solutions. J. Am. Chem. Soc. 1996, 118, 3168-3181. [CrossRef]

43. Strandman, S.; Hietala, S.; Aseyev, V.; Koli, B.; Butcher, S.J.; Tenhu, H. Supramolecular assemblies of amphiphilic PMMA-blockPAA stars in aqueous solutions. Polymer 2006, 47, 6524-6535. [CrossRef]

44. Fresnais, J.; Yan, M.; Courtois, J.; Bostelmann, T.; Bée, A.; Berret, J.F. Poly(acrylic acid)-coated iron oxide nanoparticles: Quantitative evaluation of the coating properties and applications for the removal of a pollutant dye. J. Colloid Interface Sci. 2013, 395, 24-30. [CrossRef]

45. Hu, Y.; Wang, J.; Zhang, H.; Jiang, G.; Kan, C. Synthesis and characterization of monodispersed P(St-co-DMAEMA) nanoparticles as pH-sensitive drug delivery system. Mater. Sci. Eng. C 2014, 45, 1-7. [CrossRef]

46. Bao, H.; Li, L.; Gan, L.H.; Ping, Y.; Li, J.; Ravi, P. Thermo- and pH-responsive association behavior of dual hydrophilic graft chitosan terpolymer synthesized via ATRP and click chemistry. Macromolecules 2010, 43, 5679-5687. [CrossRef]

47. Xiao, G.; Hu, Z.; Zeng, G.; Wang, Y.; Huang, Y.; Hong, X.; Xia, B.; Zhang, G. Effect of hydrophilic chain length on the aqueous solution behavior of block amphiphilic copolymers PMMA-b-PDMAEMA. J. Appl. Polym. Sci. 2012, 124, 202-208. [CrossRef]

48. Wright, D.B.; Patterson, J.P.; Pitto-Barry, A.; Cotanda, P.; Chassenieux, C.; Colombani, O.; O’Reilly, R.K. Tuning the aggregation behavior of $\mathrm{pH}$-responsive micelles by copolymerization. Polym. Chem. 2015, 6, 2761-2768. [CrossRef]

49. Fournier, D.; Hoogenboom, R.; Thijs, H.M.L.; Paulus, R.M.; Schubert, U.S. Tunable pH- and temperature-sensitive copolymer libraries by reversible addition-fragmentation chain transfer copolymerizations of methacrylates. Macromolecules 2007, 40, 915-920. [CrossRef]

50. Ahmad, Z.; Shah, A.; Siddiq, M.; Kraatz, H.-B. Polymeric micelles as drug delivery vehicles. RSC Adv. 2014, 4, 17028-17038. [CrossRef]

51. Dian, L.; Yu, E.; Chen, X.; Wen, X.; Zhang, Z.; Qin, L.; Wang, Q.; Li, G.; Wu, C. Enhancing oral bioavailability of quercetin using novel soluplus polymeric micelles. Nanoscale Res. Lett. 2014, 9, 684. [CrossRef]

52. Kaur, A.; Ribelli, T.G.; Schröder, K.; Matyjaszewski, K.; Pintauer, T. Properties and ATRP activity of copper complexes with substituted tris(2-pyridylmethyl)amine-based ligands. Inorg. Chem. 2015, 54, 1474-1486. [CrossRef]

53. Chmielarz, P.; Krys, P.; Wang, Z.; Wang, Y.; Matyjaszewski, K. Synthesis of well-defined polymer brushes from silicon wafers via surface-initiated seATRP. Macromol. Chem. Phys. 2017, 218, 1700106. [CrossRef] 